\title{
Nitric oxide, cell death and increased taxol recovery Don J Durzan*
}

\author{
Address: Department of Plant Sciences, University of California, One Shields Ave. Davis, CA 95616, USA \\ Email: Don J Durzan* - djdurzan@ucdavis.edu \\ * Corresponding author
}

from Cell Biology of Nitric Oxide and Cell Death in Plants

Yalta, Ukraine, 8-II September 2004

Published: 3I May 2005

BMC Plant Biology 2005, 5(SuppI I):SI2 doi:I0.I I86/I47I-2229-5-SI-SI2

\section{Background}

With NASA support this research aimed at evaluating early opportunities in Microgravity Sciences to commercialize space and to develop the biotechnology facility for the International Space Station [1]. The main task was to evaluate the production of taxol (generic name: paclitaxel) with cell suspensions in bioreactors designed for the Space Shuttle. Unexpectedly, this work led to the early demonstration of L-arginine-dependent nitric oxide (NO) bursts in mechanically and gravitationally stressed plant cells, to NO-induced programmed cell death (apoptosis) (reviewed in [2]), and to a model describing how these factors contribute to increased taxol and taxane recovery from conifers.

Earlier, when intermediates of the Krebs-Henseleit or urea cycle (See Figure 1) were fed to conifers, several substituted guanidino compounds were derived from uniformly labeled ${ }^{14} \mathrm{C}$-L-arginine, and less so from ${ }^{14} \mathrm{C}-\mathrm{L}-$ citrulline $[3,4]$. At that time, the substituted guanidines were considered mainly as respiratory inhibitors $[5,6]$. Today, they are natural inhibitors of plant, animal and human nitric oxide synthases (NOSs). NOS substrates are $\mathrm{L}$-arginine and oxygen. NOS products are L-citrulline and NO.

Since nitrate and nitrite reductases were also known sources of $\mathrm{NO}$, we obtained an Arabidopsis nitrate reductase double mutant with the aim of finding out if cells could produce NO in the absence of nitrate, nitrite, and their reductases [7]. With this mutant we reaffirmed that the source of NO was putative NOS activity. The production of NO from L-arginine was blocked by D-arginine, and by the NOS inhibitor, $N^{G}$-monomethyl-L-arginine (LNMMA) ensuring that NO was produced in the absence of any residual nitrate reductase activity. NOS-dependent
NO production in cells was inhibited by other guanidino compounds but not by D-arginine. Subsequently, the discovery by others of two plant NOS genes provided evidence that plant genomes code for NOS. In our work with Taxus cell suspensions, the substituted guanidines offered protection against mechanically induced stress and celldeath or apoptosis.

Taxol is an effective anti-cancer agent that was first isolated from the bark of Taxus brevifolia [8]. Taxol binds to microtubules thereby offering a novel mechanism of blocking cell proliferation. It became the best-selling anticancer drug in history. By 2000, commercial sales of taxol were well over $\$ 1.5$ billion. New models for taxol and taxane biosynthesis emerged [9] so that taxol biosynthesis could be followed at the subcellular level by immunocytochemistry, and by laser confocal and scanning electron microscopy [10-13,20]. The use of NO donors, NOS substrates, products, inhibitors (substituted guanidines), and NO traps provided new opportunities to control the citrulline-NO cycle (See Figure 1), apoptosis, and taxol production in unit gravity, simulated microgravity, and in hypergravity.

Haploid egg cells from female trees of $T$. brevifolia were selected as the experimental material $[12,19]$. These cells are easily screened without the effects of dominance, recessive, and epistatic interactions characteristic of diploid cells. Lethal genes are directly expressed, and removed by apoptosis making cell populations genetically more uniform. Diploid cell suspensions were also established from T. cuspidata [13] needles on 3-year-old stock obtained in 1995 from Zelenka Nursery (Grand Haven MI), and from seeds of $T$. chinensis. This provided better comparisons with all other published work with using diploid cells. 


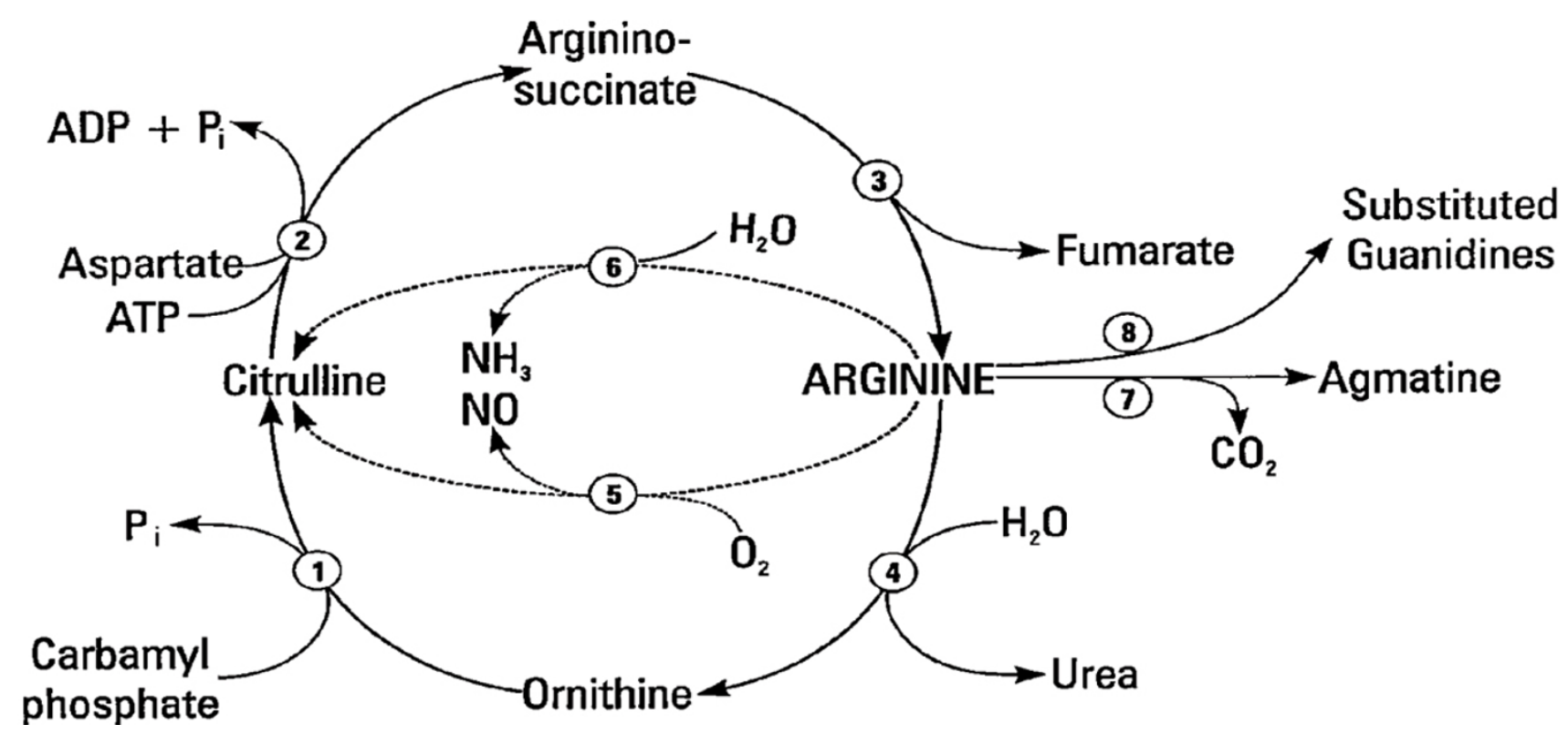

Figure I

The reactions of the Krebs-Henseleit (urea) cycle, and their relations to NOS activity. Enzymes: I. ornithine carbamoyl transferase, 2. argininosuccinate synthetase, 3. argininosuccinate lyase, 4. arginase, 5. nitric oxide synthase, 6. arginine deiminase, 7. arginine decarboxylase, 8. numerous enzymes contributing to the formation of substituted guanidino compounds. Reactions I to 4 comprise the urea cycle. Reactions 2, 3, 5, may account for NOS activity in plants (citrulline-NO cycle). Arginine deiminase was reported in chloroplasts but is mostly found in microorganisms. Reactions 7 and 8 comprise decarboxylation, oxidation, methylation, transamidination, phosphorylation, keeping the guanidino group intact or modifying it by methylation, phosphorylation, etc. They remove L-arginine as a substrate from the urea cycle, and from reactions 5 and 6 . L-arginine represents an important branch point that links nitrate and ammonium nutrition to protein synthesis and turnover (not shown), to the urea cycle, to a postulated citrulline-NO cycle, and to the formation of guanidino compounds (substituted and non substituted). Through oxygen requirements, the stress-induced NOS activity links respiration to NO, ROS and RNS production, their signaling pathways and damaging reactions, e.g., the nitration of phenols and tyrosines residues in cell regulatory proteins, and to apoptosis.

Cell suspensions were maintained in darkness at $25 \pm 2{ }^{\circ} \mathrm{C}$ on semisolid media, in $125 \mathrm{ml}$ Erlenmeyer flasks (60 $\mathrm{rpm}), 1 \mathrm{~L}$ nippled flasks on a clinostat (1 rpm simulating $2 \times 10^{-4} \times \mathrm{g}$, but with significant convective mixing of the gaseous and liquid environment), $100 \mathrm{ml}$ high-aspect rotating vessels (HARV $12.5 \mathrm{~cm}$ dia.), and rotating cylindrical culture vessels (RCCV $7.5 \mathrm{~cm}$ dia.) both at ca. $10^{-2} \times$ g (Synthecon, Houston TX). The HARV and RCCV were used by NASA in early space shuttle experiments, and in a mini-payload integration center, designed as an in-flight laboratory.

In all cell assays, apoptotic cells were distinguished morphologically and by the TUNEL reaction $[14,15]$. Free taxol, taxanes, and baccatin III in cells and the culture medium, or bound taxol and taxanes, released after xylanase activity, were determined with competitive inhibition enzyme-linked immunoassays kits from Hawaii Biotechnology. Cells were examined by laser confocal microscopy (Zeiss LSM 410 Invert Scan Microscope) using single or double-labeling immunocytochemical fluorescence (FITC, Cy3) and colloidal gold to reaffirm the subcellular locations of taxol, the taxane ring (baccatin III), the $\mathrm{C}-13$ side chain of taxol, and taxanes in general. For samples larger than $10 \mathrm{~g}$ fresh biomass, these compounds were determined by HPLC using authentic standards and taxil columns (MetaChem Technologies Inc.) [12].

\section{Results}

With T. cuspidata suspension in RCCV bioreactors $\left(10^{-2} \times\right.$ $\mathrm{g})$, and in $1 \mathrm{~L}$ nippled flasks ( 3 wks in darkness at $24^{\circ} \mathrm{C}$ ), free taxol comprised 42 and 21 percent of the total taxanes (1.1 and $2.4 \mathrm{mg}$ taxol $/ \mathrm{kg}$ air-dry biomass weight), respectively [13]. Centrifugation of cells at 3 and $24 \times$ g greatly increased taxane content but reduced taxol recovery. $T$. cuspidata and T. brevifolia responded similarly to mechanical stresses, simulated microgravity, and hypergravity by 
producing NO bursts, apoptosis, and by the overproduction of taxol and taxanes.

T. brevifolia heat-killed cells did not produce NO. Generally $19 \%$ of the live cells (unit gravity in shaker flasks for $3 \mathrm{~h}$ ) were always positive for NO as assayed with DAF2DA. With the addition of $10^{-4} \mathrm{mM} \mathrm{SNP}$, a NO donor, or after centrifugation at $150 \times \mathrm{g}$ for $3 \mathrm{~h}$, nearly all cells produced NO. However, if $0.5 \mathrm{mM}$ L-NMMA (NOS inhibitor) was added, only $26 \%$ of the cells produced NO. When 0.5 mM D-NMMA, a non inhibitor of NOS, was added, $92 \%$ of the cells produced $\mathrm{NO}[14]$.

The greater the NO produced and released by cells, the more cells became apoptotic. Additions of SNP (10-6 to $10^{-2} \mathrm{mM}$ ) increased apoptosis from 18 to $75 \%$. Centrifugation at $150 \mathrm{~g}$ yielded $35 \%$ apoptosis. This was reduced to less than $10 \%$ by the addition of the NOS inhibitor, LNMMA. Substituting D-NMMA for L-NMMA resulted in apoptosis ( $32 \%$ cells), but this was not significantly different from the cells exposed to $150 \mathrm{~g}$ [14]. The NOS requirement for oxygen connected NO production to the stressinduced and damaging increases in free radicals, viz., reactive oxygen species and reactive nitrogen species [2]. The lesson learned offered guanidino compounds as countermeasures to NO-mediated stress and apoptosis.

At unit gravity and after $10 \mathrm{~d}$, egg cells exposed to SNP (10${ }^{4} \mathrm{mM}$ ) produced $18 \mathrm{mg}$ taxol$/ \mathrm{Kg}$ fresh weight. This taxol yield was now $64 \%$ higher than the controls without SNP. The number of cells producing NO with SNP was $86.7 \%$ higher than the controls without SNP. By contrast, the addition of L-NMMA $(0.5 \mathrm{mM})$ decreased NO production by $87.3 \%$. Taxol yield was reduced by $75 \%(4.1 \mathrm{mg} / \mathrm{Kg}$ fresh weight) (unpublished results).

In a separate study at unit gravity with cells supported on filter paper, the effects of SNP $\left(10^{-4} \mathrm{mM}\right)$, sodium tungstate, (a nitrate reductase inhibitor at $1 \mathrm{mM}$ ), and LNMMA $(0.5 \mathrm{mM})$ were used to evaluate taxol yields after 5 d. SNP added alone, or tungstate with SNP together, yielded taxol at 8.0 and $8.1 \mathrm{mg} / \mathrm{Kg}$ fresh weight, respectively, i.e., the differences were not significantly different. This reaffirmed that nitrate reductase activity was not a contributor to NO-dependent taxol production. L-NMMA alone, or together with added tungstate, reduced taxol recovery to 2.1 and $2.0 \mathrm{mg} / \mathrm{kg}$ fresh weight, respectively. Here again, NOS was responsible for the NO that increased taxol production without a significant contribution from nitrate reductase. Removing and starving the control egg cells only slightly increased taxol recovery.

The tetracyclic diterpenoid ring of taxol is synthesized by cyclization of geranylgeranyl diphosphate to give taxa$4(5), 11$ (12(-diene) in plastids and in light and darkness
$[9,11]$. This basic ring structure gives rise to over 300 different taxanes. One of these, baccatin III, can provide the ring structure for the biosynthesis of taxol. Although the mechanisms are not yet clear, taxol formation also requires the addition of a $\mathrm{C}-13$ side-chain originating from phenylalanine. Additional and finishing structural changes for taxol involve reaction in the endoplasmic reticulum and Golgi stacks.

Using specific antibodies, the biosynthesis of the taxol ring in plastids, and the cytoplasmic assembly of bound taxol and related taxanes were visualized by laser confocal and scanning electron microscopy. Gold labeling was especially useful to identify taxol and taxanes in transport vesicles, the plasmalemma, cell walls, and in the culture medium. Colloidal $40 \mathrm{~nm}$-gold-immunolabeled antibodies to taxanes, taxol, and baccatin III were visualized with 7 to $21 \mathrm{nM}$ sensitivity, with and without gold backscatter (laser confocal and scanning electron microscopy).

In egg cells, baccatin III (taxane ring) was detected in gravisensing amyloplasts and vesicles associated with plastid membranes. Baccatin III, taxol, and other taxanes were transported through the cytoplasm by these vesicles, which then released their contents to the plasma membrane. Plastids, that moved and docked at the plasma membrane, also released bound taxol and taxanes into the plasma membrane. The bound taxol and taxanes at the cell-surface were deposited in newly formed cell walls or released into the culture medium. The drug-productive cells and materials in the culture medium containing bound taxol, baccatin III, and taxanes were collected with antibody-labeled paramagnetic beads [16]. Immunogoldlabeled taxol, taxanes and baccatin III were detected in transport vesicles, plasma membrane fragments, and on materials recovered from the culture medium.

Bound taxol and taxanes were recovered from xylanase (commercial and purified) hydrolysates of cell biomass, debris in the culture medium, and from the wood of trees. Taxol and other taxanes were characterized and identified by HPLC using authentic standards. Results indicated that recovered taxol was bound to xyloglucan oligosaccharides. Probes of cells with an antibody to xyloglucan endotransglycosylases implied that 'touch' genes normally expressed under mechanical forces [18], could have provided additional sites for the attachment of taxol and other taxanes.

In hypergravity ( 3 to $150 \times \mathrm{g}$ ), the taxol and taxanes released from cells by syneresis, were recovered on hydrophobic PVDF (polyvinylidene fluoride) filters. Cyclodextrins added to the culture medium enhanced biomass yield and altered the solubility of taxanes to improve the recovery of taxol and taxanes. The addition of 
cyclodextrins to the culture medium improved cell biomass and taxol recovery [17]. Further details are available in US Patents [16-18,20].

\section{Acknowledgements}

This work was impossible without the support from NASA's Microgravity Grant No. 9-825. Special thanks go to Mr. Frank Ventimiglia for determining and locating taxol in the cell suspensions. Dr. Cristina Pedroso and Helena Garcks carried out the NO, TUNEL and NOS- related studies. Drs. H-C Dong and $\mathrm{C}$. Pedroso contributed to the taxol assays using the protocols worked out by F. Ventimiglia. A post-doctoral fellowship from China for Dr. Dong (China) aided in studies with NO and taxol. Dr. Dorward at the National Institutes of Health, Rocky Mountain Laboratory, prepared the scanning electron micrographs.

\section{References}

I. Durzan DJ: Metabolic engineering plant cells in a space environment. Biotechnol Genet Eng Rev 2000, 17:349-383.

2. Durzan DJ, Pedroso MC: Nitric oxide and reactive nitrogen oxide species in plants. Biotechnol Genet Eng Rev 2002, 19:293-337.

3. Durzan DJ: Nitrogen metabolism of Picea glauca. I. Seasonal changes of free amino acids in buds, shoot apices and leaves, and the metabolism of uniformly labeled ${ }^{14} \mathrm{C}$-L-arginine by buds during the onset of dormancy. Can J Bot 1968, 46:909-919.

4. Durzan DJ: Nitrogen metabolism of Picea glauca. IV. Metabolism of uniformly labeled ${ }^{14} \mathrm{C}$-L-arginine, [carbamyl-14C]-Lcitrulline, and $\left[1,2,3,4-{ }^{14} \mathrm{C}\right]-\gamma$ guanidinobutyric acid during diurnal changes in the soluble and protein nitrogen associated with the onset of expansion of spruce buds. Can J Biochem 1969, 47:77|-783.

5. Durzan DJ, Steward FC: Nitrogen metabolism. In Plant Physiology, An Advanced Treatise Volume 8. Edited by: Steward FC. Academic Press, Inc., New York; 1983:55-265. Chapt. 2

6. Bidwell RGS, Durzan DJ: Some recent aspects of nitrogen metabolism. In Historical and Recent Aspects of Plant Physiology: A Symposium Honoring FC Steward Cornell Univ Press, College Agriculture and Life Science; 1975:162-227.

7. Garcks H, Durzan DJ, Pedroso MC: Mechanical stress elicits nitric oxide formation and DNA fragmentation in Arabidopsis thaliana. Annals Bot 200I, 87:567-574.

8. Goodman J, Walsh V: The story of taxol. Nature and politics in the pursuit of an anti-cancer Drug. Cambridge Univ Press, Cambridge; 200I:282.

9. Jennewein S, Croteau R: Taxol: biosynthesis, molecular genetics, and biotechnological applications. Appl Microbiol Biotech 200I, 57:13-19.

10. Grothaus P, Bignami GS, O'Malley S, Harada KE, Byrnes JB, Waller DF, Raybould TJ: Taxane-specific monoclonal antibodies: Measurement of taxol, baccatin. Nat Prod 1995, 58: I003-1004.

II. Durzan DJ: Gravisensing, apoptosis, and drug recovery in Taxus cell suspensions. Gravit Space Biol Bull 1999, I 2:47-55.

12. Durzan DJ, Ventimiglia F: Free taxanes and the release of bound compounds having taxane antibody reactivity by xylanase in female, haploid-derived cell suspension cultures of Taxus brevifolia. In Vitro Plant Cell Devl Biol I994, 30P:2 I 9-227.

13. Durzan DJ, Ventimiglia F, Havel L: Taxane recovery from cells of Taxus in micro- and hypergravity. Acta Astronautica 1998, 42:455-463.

14. Pedroso MC, Magalhaes JR, Durzan DJ: Nitric oxide induces cell death in Taxus cells. Plant Sci 2000, 157:173-181.

15. Havel L, Durzan DJ: Apoptosis in plants. Bot Acta 1996, 109:268-277.

16. Durzan DJ, Ventimiglia F: Recovery of taxanes from plant material. US Patent 1999. No.5,98I,777. November 9. (Use of paramagnetic beads)

17. Durzan DJ, Ventimiglia F: Cyclodextrins in plant nutrient formulations. US Patent 2000. No.6,087, I76. July II

18. Durzan DJ, Ventimiglia F: Taxane production in haploid-derived cell cultures. US Patent 1996. No.5,5547,866. November 9

19. Antosiewicz DM, Purugganan MM, Polisensky DH, Braam J: Cellular localization of Arabidopsis xyloglucan endotransglycosylase- related proteins during development and after wind stimulation. Plant Physiol 1997, I I 5:1319-1328

20. Durzan DJ, Ventimiglia F: Recovery of taxanes from conifers. US Patent 1999. No.5,955,62I. September 2I. (screening taxanes from Coniferales)
Publish with Biomed Central and every scientist can read your work free of charge

"BioMed Central will be the most significant development for disseminating the results of biomedical research in our lifetime. "

Sir Paul Nurse, Cancer Research UK

Your research papers will be:

- available free of charge to the entire biomedical community

- peer reviewed and published immediately upon acceptance

- cited in PubMed and archived on PubMed Central

- yours - you keep the copyright 